\title{
Massive Adherent Placenta, Placenta Percreta
}

\author{
Eric Edwin Yuliantara'), Nutria Widya Purna Anggraini²), \\ Dympna Prameilita Prisasanti3)
}

\author{
Department of Obstetrics and Gynecology, Faculty of Medicine,Universitas Sebelas Maret/ \\ dr. Moewardi Hospital, Surakarta
}

\section{ABSTRACT}

Background: Adherent placentas including placenta accreta, increta and percreta are conditions where there is abnormal implantation of all or part of the placenta on the myometrial wall. Massive adherent placenta has high morbidity and mortality rates in both mother and fetus. There is a positive correlation between the incidence of adherent placenta and the increase in cesarean section rates worldwide. Identification of risk factors, antenatal diagnosis, accurate preoperative preparation, multidisciplinary management, and appropriate counseling are the main management of adherent placenta to reduce maternal morbidity.

Case Presentation: A woman, G5 $\mathrm{P}_{3} \mathrm{~A} 1$, age 36 years pregnant 37 weeks, complained loudly regularly since 6 hours before admission to hospital. There is a history of CS as much as $3 \mathrm{x}$ with indications of $2 x$ Premature rupture of the membranes and uterine rupture, as well as a history of curettage (1x). Physical examination showed that the general condition was good, and composting, vital signs were within normal limits. Abdomen palpable single fetus, intrauterine, elongated, head presentation, left back, moderate his (+), FHR $150 \mathrm{x} /$ minute. The results of prenatal sonography examination showed that neither placenta previa nor massive adherent placenta was found. The preoperative diagnosis was inparticular stage I latent phase with a history of SC 3 times.

Results: An emergency Caesarean section was performed. Durante surgery showed severe adhesions of the placenta, uterine wall and bladder. The diagnosis of placenta percreta was confirmed, uterine resection was performed on the perreta section, hysterography as well as adhesiolysis and MOW sterilization. The results of the PA examination support the diagnosis of placenta percreta.

Conclusion: Massive adherent placenta, placenta percreta was not diagnosed in this case because there were no clinical features or prenatal sonography that supported the diagnosis of placenta percreta. A history of trauma to the uterus due to uterine rupture, history of CS and curettage were risk factors for placenta percreta in this case. The incidence rate of placenta percreta with a history of SC 3 times without placenta previa on the previous sonographic examination was $0.1 \%$. Operative management to manage bleeding and post operative care have been carried out according to the procedure so as to avoid mortality.

Keywords: massive adherent placenta, placenta percreta, case report

\section{Correspondence:}

Eric Edwin Yuliantara. Department Obstetrics and Gynecology, Faculty of Medicine Universitas Sebelas Maret/ dr. Moewardi General Hospital Surakarta. Jl Kolonel Sutarto 132, Surakarta, Central Java. Email: edwinericog@staff.uns.ac.id. Mobile: 08122618769.

Cite this as:

Yuliantara EE, Anggraini NWP, Prisasanti DP (2021). Massive Adherent Placenta, Placenta Percreta. J Matern Child Health. 06(01): 108-121. https://doi.org/10.26911/thejmch.2021.06.01.11.

(c) (i) (-) Journal of Maternal and Child Health is licensed under a Creative Commons Journal of Maternal and Child Health is licensed under a Creative Con
Attribution-NonCommercial-ShareAlike 4.o International License.

\section{BACKGROUND}

Massive adherent placenta (MAP) is a condition in which there is abnormal im- plantation of all or part of the placenta in the myometrial wall. Adherent placentas include placenta accreta, increta and 
percreta which are distinguished by the depth of penetration of the placenta to the myometrial wall (Dwyer et al., 2008).

Placenta accreta is a condition in which superficial adhesions of the placental villi occur without invasion of the myometrium; placenta increta is a condition where the placental villi invade into the myometrium; placenta percreta is a state of the placental villi that invade deeper into the serous layer to other intra-abdominal organs such as the bladder. Approximately $75 \%$ of adherent placentas are placenta accreta, $18 \%$ are placenta increta, and $7 \%$ are placenta percreta (Dola and Longo, 2006).

MAP is a life-threatening condition, with high rates of maternal and fetal morbidity and mortality. The incidence of placenta accreta has increased steadily, reporting from one in 30,000 deliveries in 1950 to one in 2500 deliveries (a ten-fold increase) in 1997 (Committee opinion, 2012; Tantbirojn et al., 2008). This striking increase is associated with an increase in the rate of cesarean section worldwide. One study estimates that a continuous increase in the rate of cesarean section can lead to an increased incidence of MAP and maternal mortality.

Most women with MAP have identifiable risk factors (Garmi and Salim, 2012). Placenta previa and a history of previous cesarean delivery are major risk factors. The risk increases with the number of previous cesarean sections (McGraw, 2010; Comstock, 2011). Trauma or damage to the myometrial wall and scarring due to repeated dilatation or curettage, are also risk factors for developing placenta accreta. Other risk factors include maternal age, multiparity, previous history of other uterine surgeries, Asherman syndrome, leiomyoma, uterine anomalies, hypertension in pregnancy, and smoking (Committee opinion, 2012; Belfort, 2010; Berkley and Abuhamad, 2013).

The average patient with placenta accreta is asymptomatic. Possible symptoms are vaginal bleeding and abdominal cramps, which are mostly seen in cases where placenta previa is the biggest risk factor for placenta accrete (Belfort, 2010). The exact pathogenesis of placental accreta has not been identified. There is a hypothesis that the pathogenesis stems from impaired development of the decidua, excessive trophoblast invasion, or a combination of both.

Management of women with placenta accreta is usually by cesarean section. It is due to invasion of the placenta into the myometrium, the risk of severe bleeding increases, requiring large blood transfusions and often caesarean hysterectomy to control significant blood loss (Belfort, 2010). Apart from that, prevention of complications also needs to be carried out and requires approaches from various fields (Warshak et al., 2010; Sivasankar, 2012).

Complications with MAP include damage to local organs, postoperative bleeding, amniotic fluid embolism, disseminated intravascular coagulation (DIC), multiple blood transfusions, acute respiratory distress syndrome, postoperative thromboembolism, infectious morbidity, multisystem organ failure, and death (Berkley and Abuhamad, 2013).

Because of the high morbidity associated with this condition an accurate preoperative diagnosis is required. Identification of risk factors, accurate antenatal and preoperative diagnosis, multidisiciplinary management, and appropriate counseling are the main management of placenta accreta to reduce maternal morbidity. Antenatal sonography can be used to support diagnosis and clinical management for optimal outcome (Warshak et al., 2010). 


\section{CASE PRESENTATION}

A woman, G5P3A1, 36 years old, 37 weeks pregnant, comes with complaints of regular speeding which are felt since 6 hours before admission to the hospital, amniotic fluid Table 1. Laboratory Examination

\begin{tabular}{cccc} 
HB & 12 & HbsAg & NON REACTIVE \\
Hct & 35 & PT & 12.3 \\
AL & 9.9 & APTT & 27.9 \\
AT & 246 & INR & 0.94 \\
AE & 3.78 & GDS & 77 \\
MCV & 91.9 & Na & 134 \\
MCH & 31.7 & K & 3.4 \\
MCHC & 34.4 & $\mathbf{C l}$ & 102 \\
Eos & 0.80 & & \\
Bas & 0.10 & & \\
Neu & 69.60 & & \\
Lymp & 23.30 & & \\
Mon & 6.20 & & \\
\hline
\end{tabular}

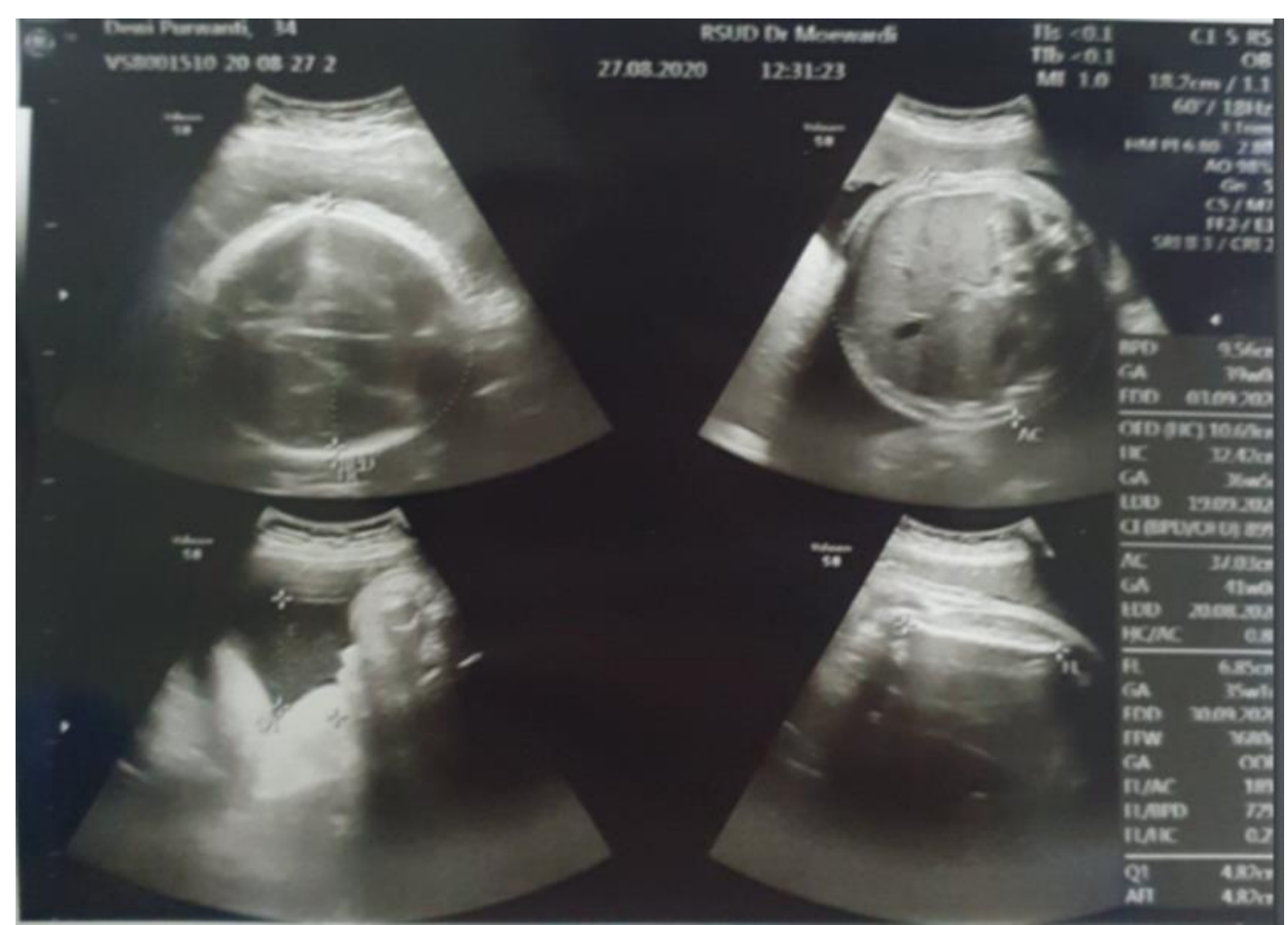

Figure 1. Ultrasound examination.Single intrauterine fetus, FHR (+).BPD 9.56 cm - 29 weeks.HC $32.42 \mathrm{~cm}-36+5$ weeks.AC $37.03 \mathrm{~cm}-41$ weeks. FL $6.85 \mathrm{~cm}$ - 35 weeks.EFW 3680 grams. It appears that placental insertion in the anterior corpus does not obscure OUI. It appears that the amniotic fluid is sufficient (SDP

Patients are those who are with a history of cesarean section (SC) three times for the indication of premature rupture of membranes and uterine rupture, as well as has not been felt, fetal movement is still felt, blood mucus (+). History of bleeding from the birth canal during pregnancy is refuted.

\section{$4.82 \mathrm{~cm})$. There was no clear major congenital abnormality.}

a history of curettage once. History of hypertension, asthma, heart disease, diabetes mellitus, and allergies is denied. Antenatal care history (ANC) routines are 
three times in midwives, and nine times in obstetrics and gynecology specialists.

Physical examination revealed that the patient's general condition was good, komnposmentis. Blood pressure $120 / 70$ $\mathrm{mmHg}$, pulse $82 \mathrm{x}$, temperature $36.7^{\circ} \mathrm{C}$, and respiration 20 times/minute. The conjuncttival eye is not anemic, the sclera is not icteric. Thorax is within normal limits. Abdomen supple, non-tender, palpable single fetus, intrauterine, elongated with left back, head presentation, his (+) 2x/ 10'/
30", regular $150 \mathrm{x} / \mathrm{m}$ FHR, $36 \mathrm{~cm}$ TFU, 3875 gram TBJ.

On genital examination, VT showed a calm urethral vulva, vaginal wall within normal limits, soft portio, $1 \mathrm{~cm}$ opening, amniotic fluid (-), blood mucus (+). Laboratory tests are described in Table 1.

Fetomaternal sonography results show; good fetal anatomy, good fetal well being, and good fetal growth. The complete ultrasound and CTG screening examinations are described in Figure 1, Figure 2, Figure 3, and Figure 4.
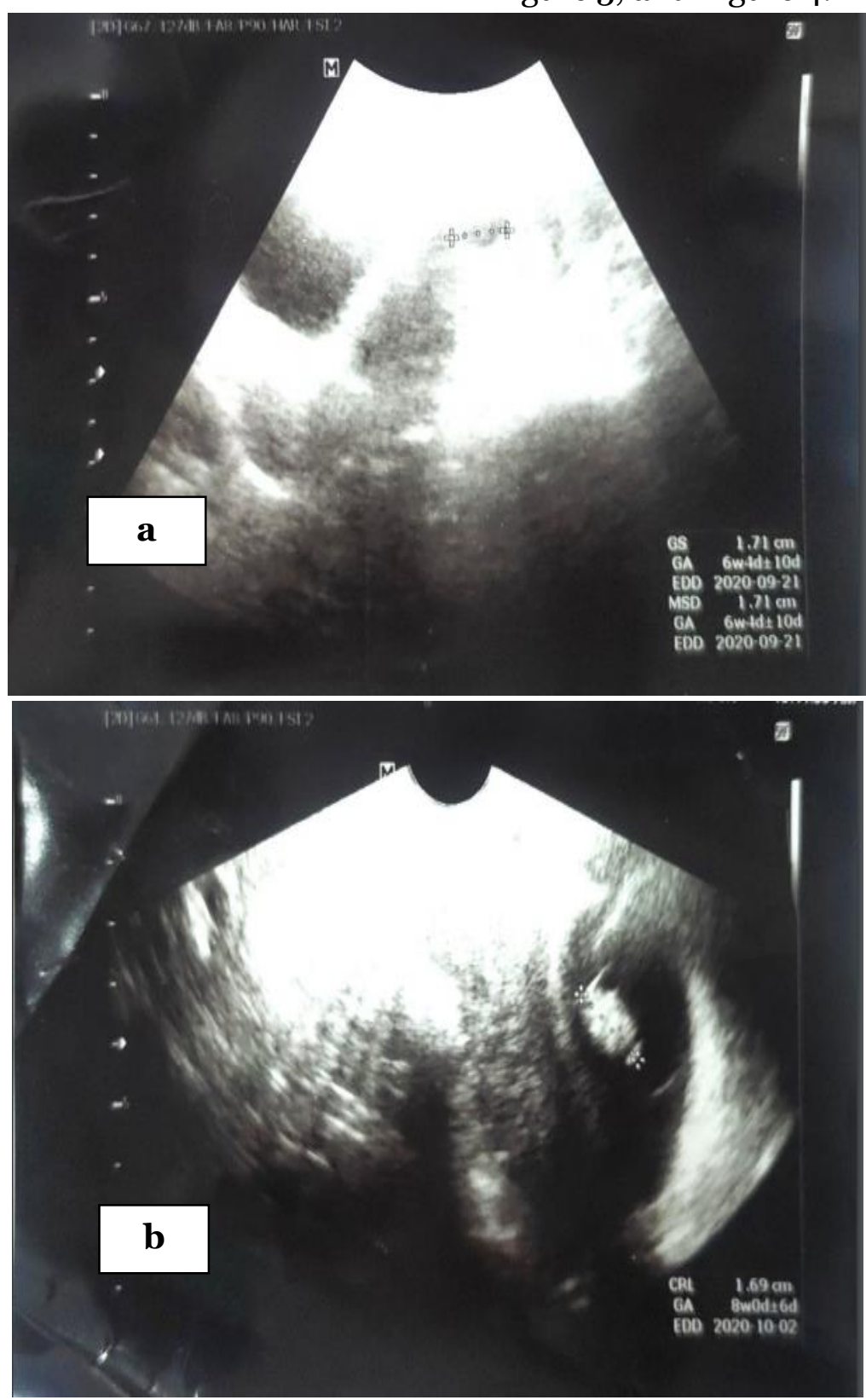
Yuliantara et al./ Massive Adherent Placenta, Placenta Percreta

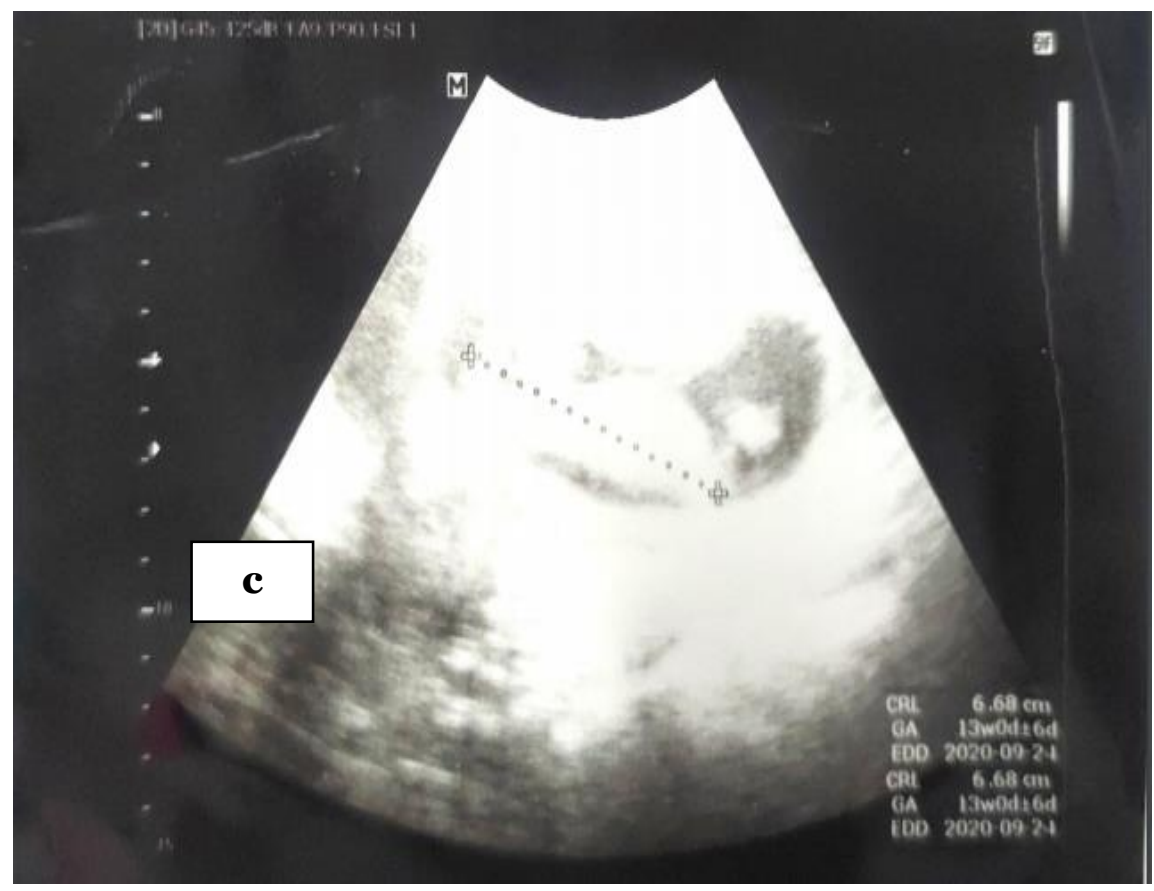

Figure 2. Ultrasound examination, (a) 6 weeks of age, (b) 8 weeks of age, (c) 13 weeks of age

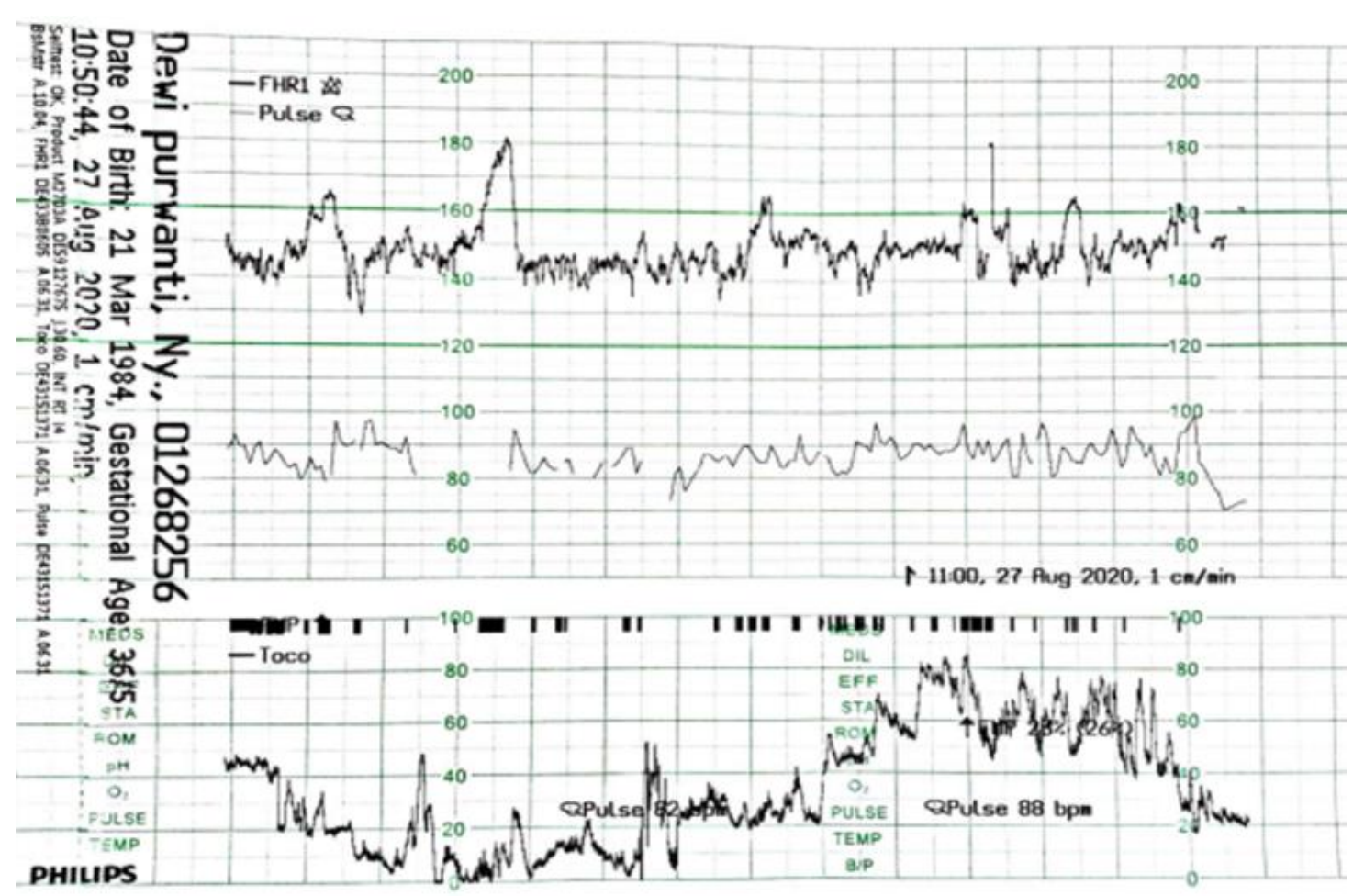

Figure 3. CTG examination.Baseline 145. Variability $>$ 10. Acceleration $(+)$. Deceleration $(+)$. Fetal movement $(+)$. Contraction $(+)$. CST category 1. 
Yuliantara et al./ Massive Adherent Placenta, Placenta Percreta

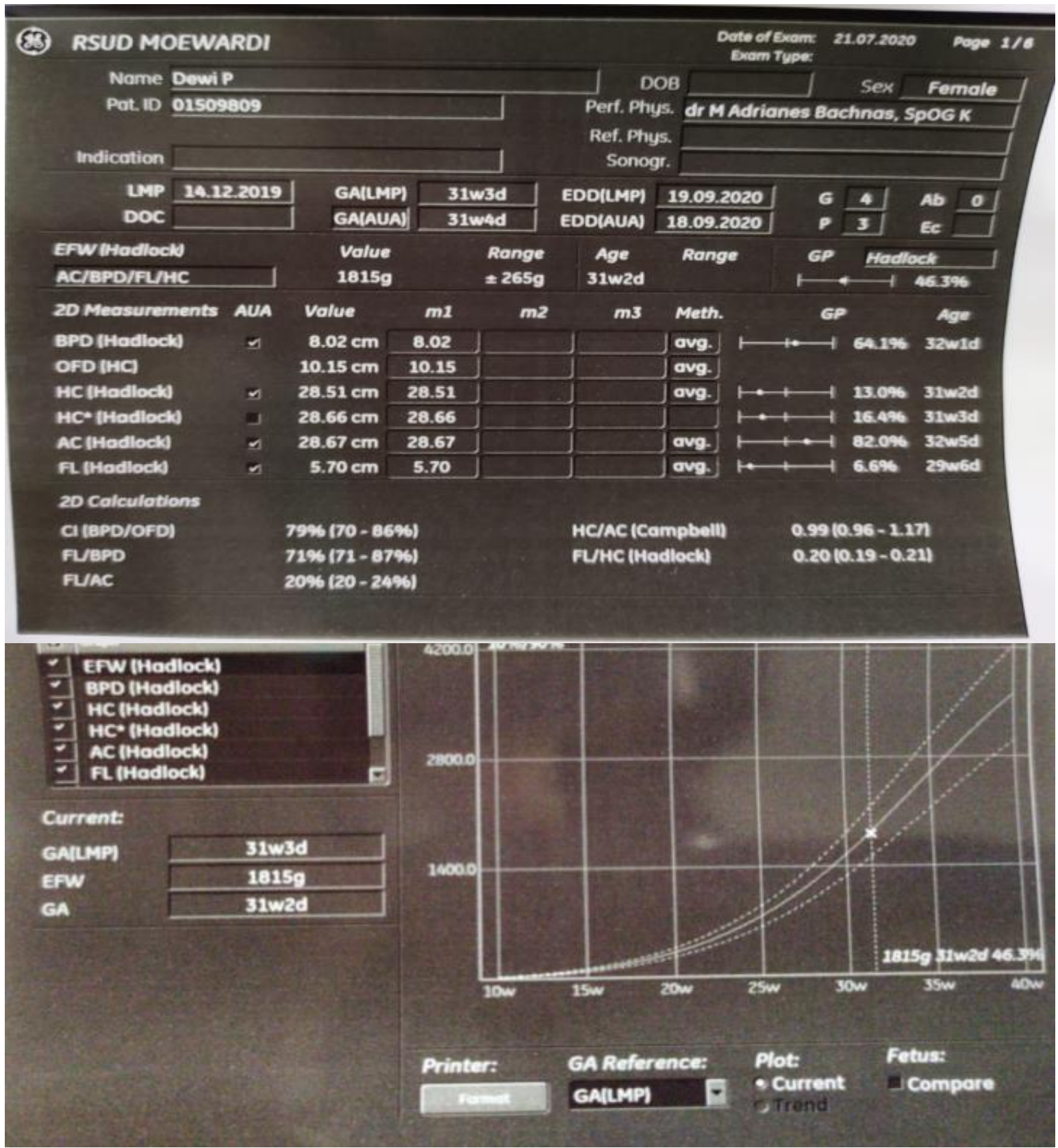


Yuliantara et al./ Massive Adherent Placenta, Placenta Percreta
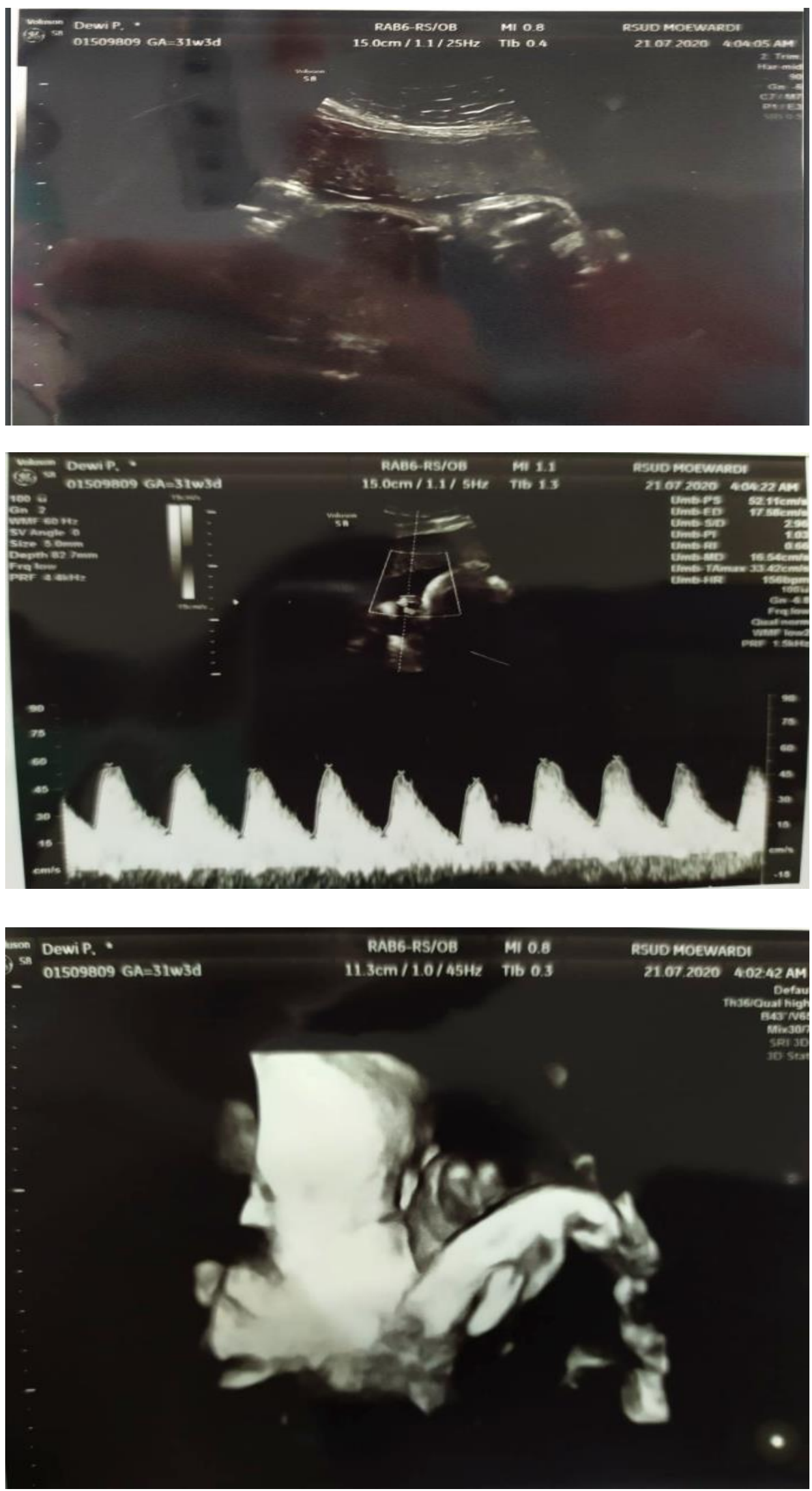


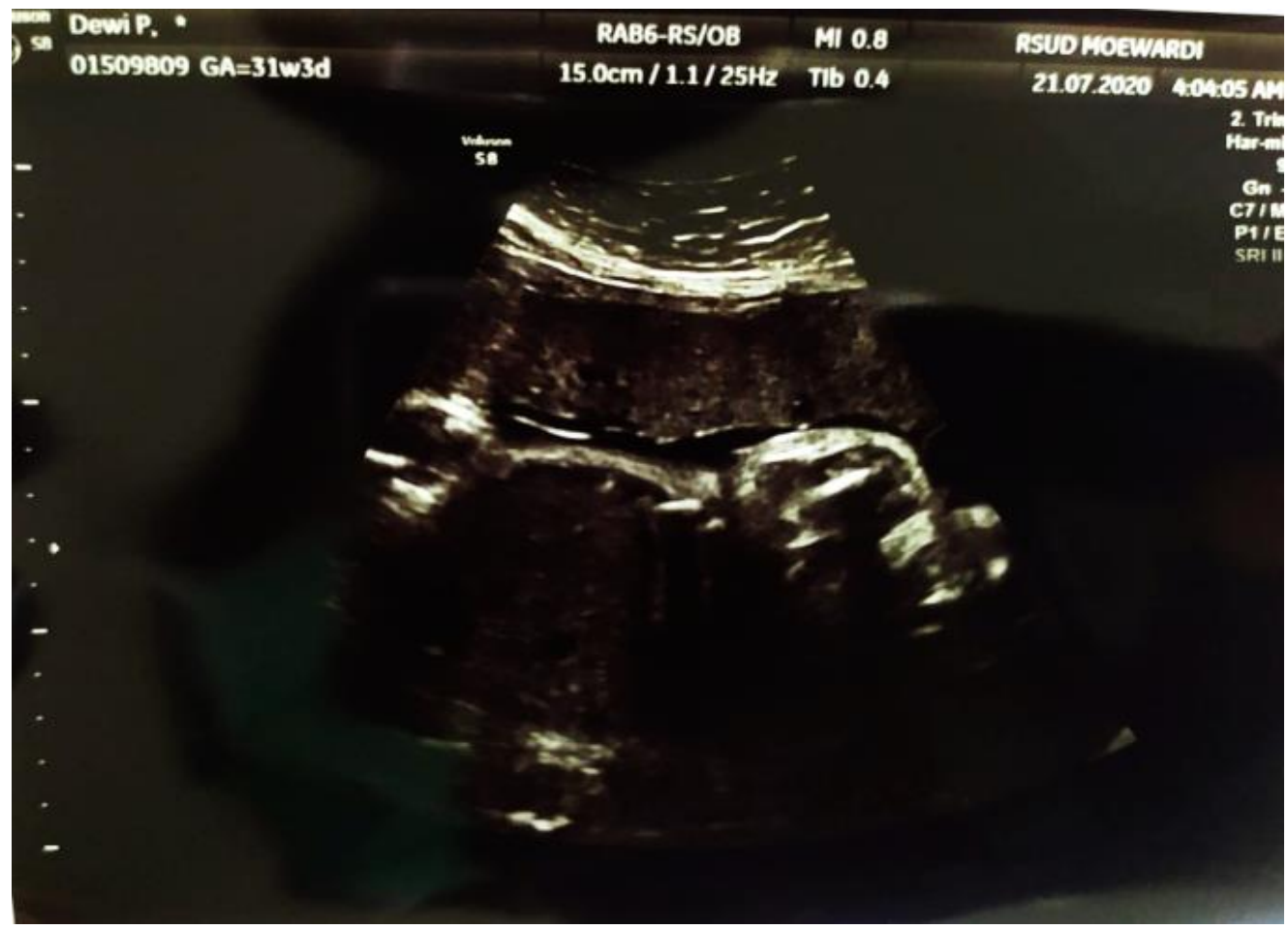

Figure 4. Fetomaternal Ultrasound Screening. Single fetus intrauterine head presentation. Biometry according to UK 31 weeks. PIE. Anterior dominant placenta does not obscure OUI. Lakuna grade 1. Bridging vessel (-). Good retroplacental clear space. SBR 4.7mm thick. HC / AC equal TBJ $1.8 \mathrm{~kg}$ is appropriate. Normal amniotic fluid 6,7. Head: structure of the cerebrum, lateral ventricles, cerebellum, posterior fossa and normal craniofacial. Thorax: Good CTR, good heart structure. Abdomen: good stomach, good abdominal structures. Pelvis: Ren, VU and tractus. normal urinarius, genital daughter. Eksterimitas: normal shape and size.

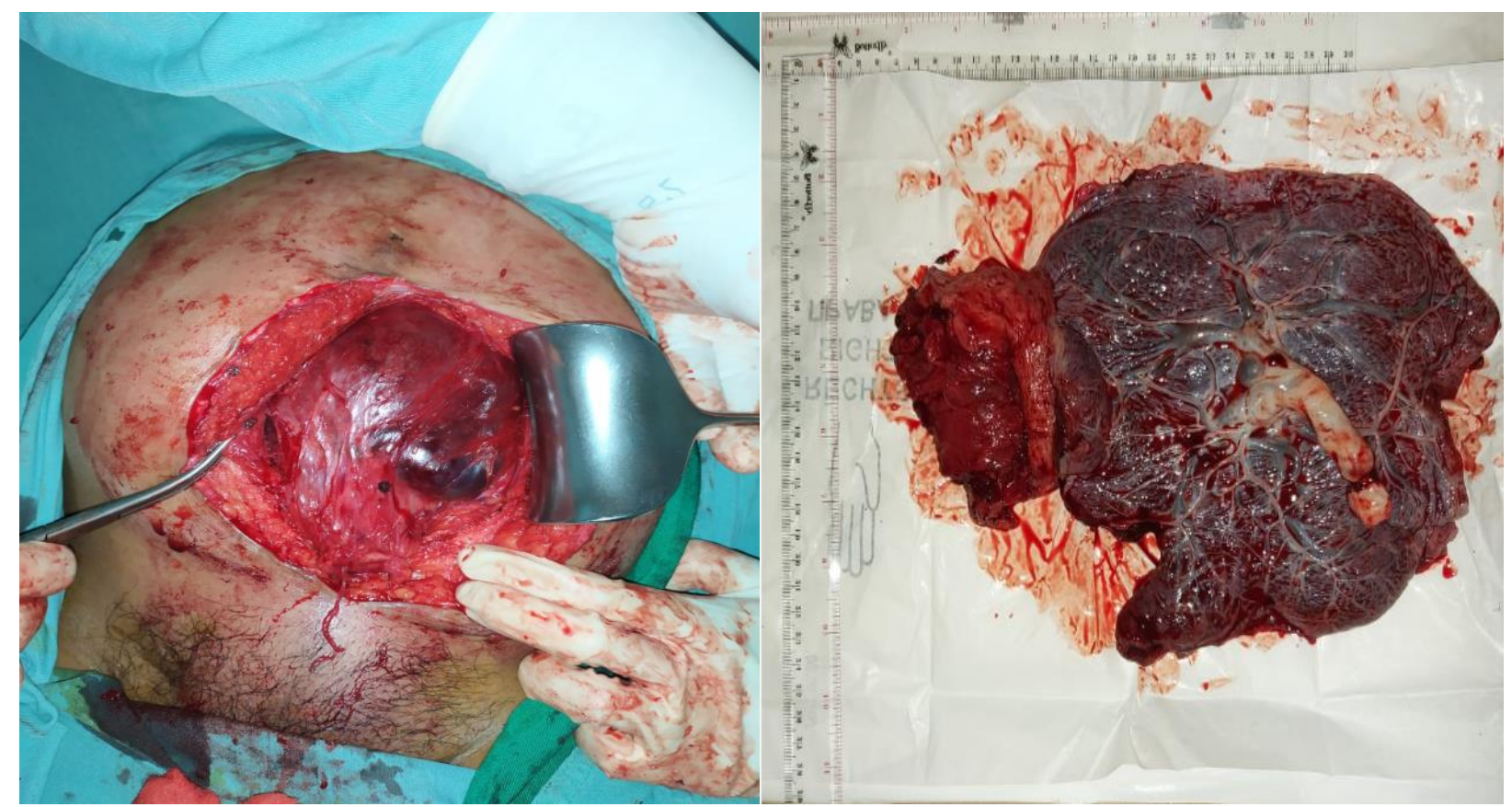

Figure 5. Perreta placenta 


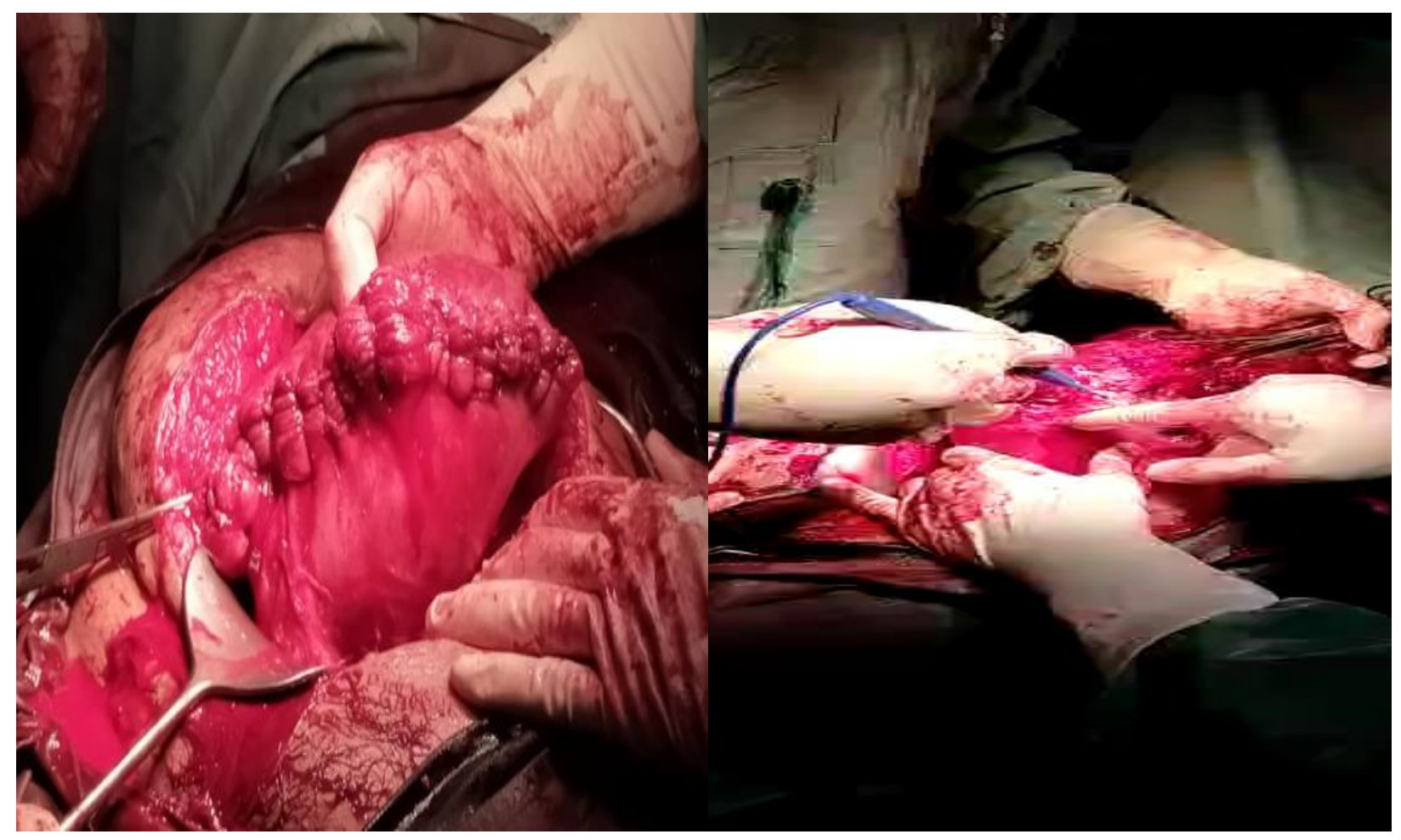

Figure 6. Post hysterographic uterus

\section{RESULTS}

Patient diagnosed with G5 $\mathrm{P}_{3} \mathrm{~A} 1$, gestational age 37 weeks, latent phase I of the first stage of pregnancy, with a history of SC 3x. Patients were subjected to emergency sectio and MOW sterilization, blood supply 4PRC, $4 \mathrm{WB}, 4 \mathrm{FFP}, 4 \mathrm{TC}$.

At the time of Caesarean section, a gravid uterus was found, it appears that the placenta has penetrated the uterine serosa (bulging) in the anterolateral corpus, and it appears that the lower uterine segment has adhesions to the bladder. Diagnosis of placenta percreta. Figure 5 illustrates the condition of the uterus during surgery.

Born female infants, birth weight 3,500 grams, US 6-7-9. Uterine resection was performed on the perreta section, hysterography as well as adhesion and MOW sterilization with bleeding during $4500 c c$ surgery.

Postoperatively, the patient was admitted to the ICU, transfused with 4 PRC and 3 FFP.
From the results of anatomical pathology (PA), it was found that the choreal villi proliferation was partially bordered by the uterine wall and the proliferation of blood vessels, there were no signs of malignancy. The PA results concluded that this patient's diagnosis was favorable towards placenta percreta.

Postoperative care for the patient is 5 days then outpatient and routine control at the obstetrician hospital Dr. Moewardi. The patient was well and had no signs of postoperative bleeding or other complications.

DISCUSSION
In this patient, a history of $3 \mathrm{x}$ cesarean
section surgery and curettage were the
biggest factors in the occurrence of placenta
percreta. It was reported that post-section
surgery increased the risk of placenta
accreta from $2 \%$ to $39 \% .7$ Having a history
of cesarean section surgery once can
increase the risk of $0.3 \%$, whereas with a
history of cesarean section surgery more


than 5 times, it can increase to $6.74 \%$ the incidence of MAP.

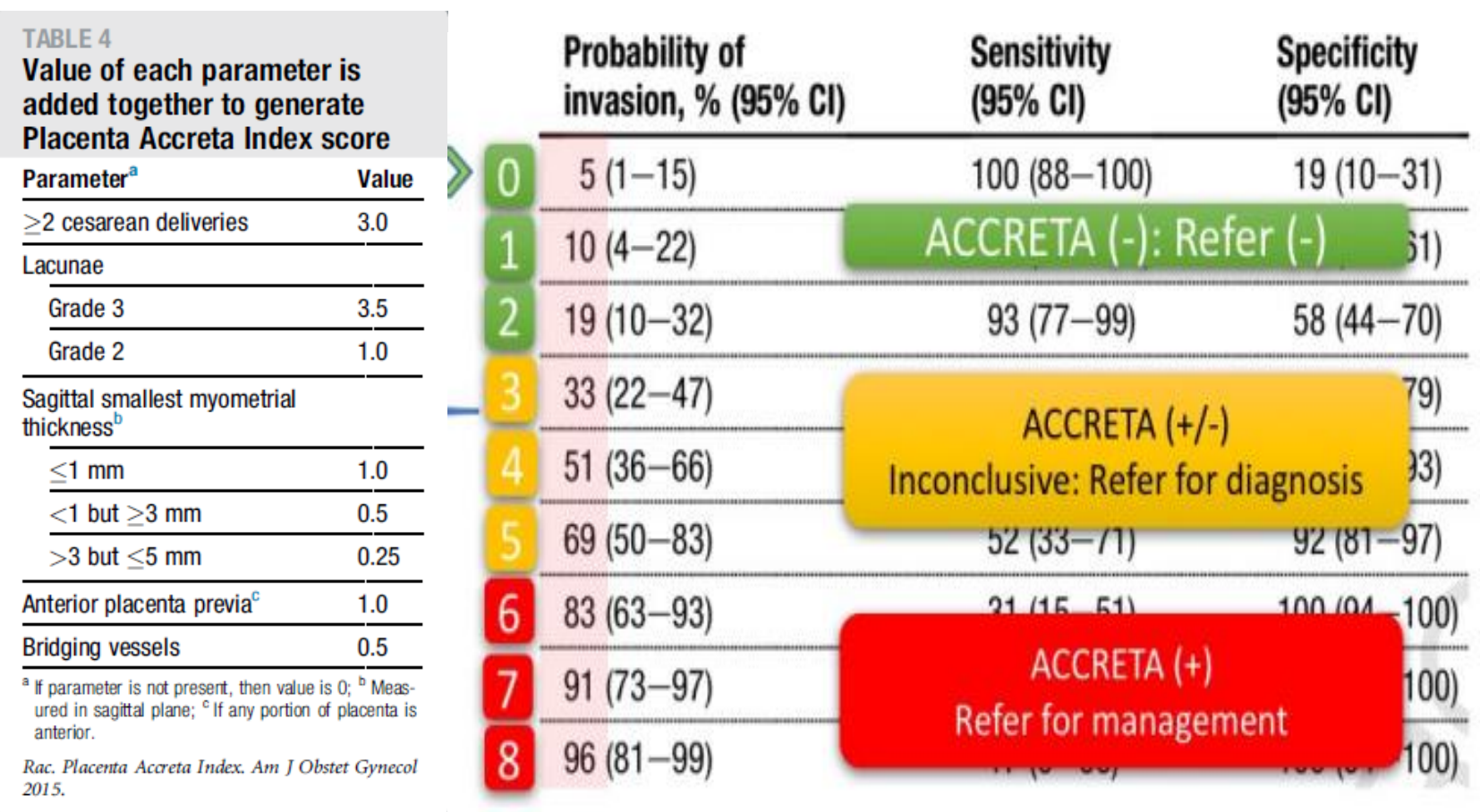

Figure 7. PAI scoring

Table 1. MAP scoring

\begin{tabular}{lc}
\multicolumn{1}{c}{ Parameter } & Score \\
\hline Number of previous cesarean deliveries & \\
1 & 1 \\
$\geq 2$ & 2 \\
Lacuna maximum dimension & \\
$\leq 2$ & 1 \\
$>2$ & 2 \\
Number of lacunae & \\
$\leq 2$ & 1 \\
$>2$ & 2 \\
Obliteration of uteroplacental demarcation & 2 \\
Location of placenta & \\
Anterior & 1 \\
Placenta previa & 2 \\
Doppler assesment & \\
Blood flow in placental lacunae & 1 \\
Hypervascularity of placenta bladder and/or uteroplacental interface & 2 \\
\hline
\end{tabular}

In addition, the patient also obtained a history of uterine rupture. The existence of trauma to the uterus due to rupture is a risk factor for placenta percreta in this case (Dwyer et al., 2008; Dola and Longo, 2006).
Another risk factor for this patient is the maternal age of 36 years, which in the study of Cleary and Godman, in women aged >35 years can increase the risk of placenta accreta.

Transvaginal and transabdominal ultrasound are complementary diagnostic 
techniques. Transvaginal ultrasound is safe for patients with placenta previa and allows more complete examination of the lower uterine segment.

Other supporting examinations are:

Magnetic Resonance Imaging (MRI). This examination is more expensive than ultrasound and requires experience and expertise in the evaluation of abnormal placental invasion. MRI is considered an additional modality to complement the diagnostic accuracy of ultrasonography.

The screening examination in this patient has been carried out with a scoring of the Placenta Accreta Index (PAI) and a scoring of the Morbidly Adherent Placenta (MAP). Figure 7 and Figure 8 describe the scoring of PAI and MAP.

In this patient, PAI scoring $=3(33 \%)$ and MAP scoring 3 (low risk). The PAI score has a sensitivity of $24 \%$ and a specificity of $100 \%$. Meanwhile, the MAP score has a sensitivity of $92.3 \%$ and a specificity of $94.1 \%$.

The technical problems that often cause false positives or negatives on the Placenta Accreta Spectrum screening are as follows:

1. Selection of transducer: transabdominal use should be with a higher frequency and must trace the area of the operation.

2. Bladder filling: without a full VU, assessment of bladder invasion, placental bulge and uterovesical hypervascularity is difficult to assess.

3. Pressure on the probe: too much pressure on the probe can eliminate the retroplacental clear zone image, this can be minimized by using TVS.

4. Color doppler blood flow assessment difficult to distinguish normal flow in the presence of increased flow.

A case report reported that women with placenta previa with an anterior or posterior placenta location were at increased risk of developing placenta accreta. The incidence of placenta accreta in this patient with a history of SC $3 x$ and the absence of placenta previa on the previous ultrasound examination was $0.1 \%$.

The undiagnosed placenta percreta in this patient was due to the absence of a typical clinical picture (painless bleeding) or sonography that led to the placenta accreta spectrum.

Neither the early trimester ultrasound nor the ANC at 31 weeks' gestation showed no signs of abnormal placental invasion.

This is indicated by the absence of a caesarean scar pregnancy and abnormal placenta implantation on the SBR. Ultrasound at term gestation and postoperative findings showed that placenta insertion was in the anterior corpus and did not obscure OUI, whereas the incidence of placenta percreta from placenta insertions without previa was very rare 0.1\% (Belfort, 2010).

Management of emergency sectio in patients with 37 weeks of gestation aims to deliver a viable baby, with a good chance of life, and prevent dangerous complications to the mother (maternal hemorrhage), reducing the likelihood of fetal death due to antepartum hemorrhage (Mascarello et al., 2017).

In this patient, the placenta percreta was performed and kept the uterus (conservative) to reduce the morbidity associated with ceaserean hysterectomy, preserving fertility. The uterus still has progesterone receptors, so that premature menopause does not occur, so that the uterus is maintained. Uterine vascularization originnates from the uterine artery (90\%) branches of the ovarian artery, and the protundum ligaments originating from the epigastric artery. However there is another vascularity. The vaginalis arteries and can normalize blood flow to the uterus even though both branches of the uterine artery 
are occluded. Palacios divides into 2 areas: $\mathrm{S} 1$ and $\mathrm{S} 2 . \mathrm{S} 1$ is predominantly vascularized by the uterine artery and a small portion of the ovarian artery, and the lower topographical area consisting of the lower uterine, cervical, and upper vaginal segments $\mathrm{S} 2$ is predominantly supplied by the vaginal artery (Osol and Mandala, 2009; Liapis et al., 2020).

According to Palacios, pre-operative screening related to uterine management in cases of abnormal placental invasion of MAP can be done by conserving the uterus in the $\mathrm{S} 1$ area, while doing hysterectomy in the S2 area (Palacios-Jaraquemada et al., 2020).

In this case, it was found that according to Palacios type 1 placental invasion, that is, the anterior segment of the uterus is thinning and the placenta reaches the peritoneal layer, without any new vesicplacental vessels or vesicouterine vessels, and between the posterior vesic wall and the uterine segment are still clearly separated. Vascularization includes the segment 1 (S1) area, which includes blood flow to the corpus-undus uteri, which is predominantly vascularized by the uterine artery and a small portion of the ovarian artery. So that conservation can still be done to maintain the uterus, and resection of the placenta percreta (Palacios-Jaraquemada et al., 2020).

In this patient, placenta percreta was not detected during prenatal because there was no suspicion that placenta previa was present on sonographic examination. However, a history of SC 3x and a history of previous curettage which is a risk factor for MAP should still be referred to a placenta acreta center for optimal management, reducing maternal and infant mortality and morbidity (Dwyer et al., 2008).

Pre-operative diagnosis by screening prenatal ultrasound examination in the case of massive adherent placenta is very important for successful management, to reduce mortality and morbidity (Garmi and Salim 2012; Chong et al., 2018).

In this patient, placenta percreta was undiagnosed because of the absence of clinical and sonographic features that support it and the incidence of placenta accreta without characteristic features is very rare (Volochovič et al., 2016).

Operative management to manage bleeding and post operative care have been carried out according to the procedure so as to avoid mortality. Suggestion: identification of risk factors and proper early diagnosis can reduce morbidity that occurs in patients (Dagi, 2005).

\section{AUTHOR CONTRIBUTION}

Eric Edwin Yuliantara, Nutria Widya Purna Anggraini, and Dympna Prameilita Prisasanti examine the placenta percreta, did abdominal surgery, evaluate the result of surgery, and did the manuscript.

\section{CONFLICT OF INTEREST}

The author states that the reporting of this case was carried out without any commercial or financial relationship which could be interpreted as a potential conflict of interest.

\section{FUNDING AND SPONSORSHIP}

None.

\section{ACKNOWLEDGEMENT}

The author would like to thank Universitas

Sebelas Maret and Dr. Moewardi Hospital.

\section{REFERENCE}

Belfort MA, Publication Committee, Society for Maternal-Fetal Medicine (2010). Placenta accreta. Am J Obstet Gynecol. 203(5):430-9. https://doi.org/10.1016/j.ajog.2010.09.013. 
Berkley EM, Abuhamad AZ (2013). Prenatal diagnosis of placenta accreta. J Ultrasound Med. 32(8): 1345-50. https://doi.org/10.7863/jum.2008.27 .9 .1275 .

Chong Y, Zhang A, Wang Y, Chen Y, Zhao Y (2018). An ultrasonic scoring system to predict the prognosis of placenta accrete: A prospective cohort study. Medicine (Baltimore). 97(35): e12111. https://dx.doi.org/10.1097\%2FMD.o oooooooooo12111.

Committee opinion (2012). Placenta accreta. Washington DC: The American College of Obstetricans and Gynecologists.

Comstock CH (2011). General obstetric sonography: prenatal diagnosis of placenta accreta. Dalam: Arthur CF, Eugene CT, Wesley L, Frank AM, Roberto JR. Sonography in obstetric an gynecology. Edisi ke-7. Tennesse.

Dagi TF (2005). The management of postoperative bleeding. Surg Clin North Am. 85(6):1191-213. https://doi.org/10.1016/j.suc.2005.10.013.

Dola C, Longo S (2006). Diagnosis and safe management of placenta previa. OBG Manag. 18(10):77-95.

Dwyer BK, Belogolovkin V, Tran L, Rao A, Carroll I, Barth R, Chitkara U (2008). Prenatal diagnosis of placenta accreta: sonography or magnetic resonance imaging?. J Ultrasound Med. 27(9): 1275-81. https://doi.org/10.7863/jum.2008.27.9.1275.

Garmi G, Salim R (2012). Epidemiology, etiology, diagnosis, and management of placenta accreta. Obstet Gynecol Int. 873929. https://doi.org/10.1155/2012/873929.

Liapis K, Tasis N, Tsouknidas I, Tsakotos G, Skandalakis P, Vlasis K, Filippou D (2020). Anatomic variations of the uterine artery. Review of the literature and their clinical significance. Turk $\mathrm{J}$ Obstet Gynecol. 17(1): 58-62. https://dx.doi.org/10.4274\%2Ftjod.galenos .2020 .33427 .

Mascarello KC, Horta BL, Silveira MF (2017). Maternal complications and cesarean section without indication: systematic review and meta-analysis. Rev Saude Publica. 51: 105. https://dx.doi.org/10.11606\%2FS1518-8787.2017051000389.

McGraw H (2010). Obsterical complications: obstetrics haemorrhage. Dalam: Cunningham, Leveno, Bloom, Hauth, Rouse, Spong. Williams obstetrics. Edisi ke-23. Texas.

Osol G, Mandala M (2009). Maternal Uterine vascular remodeling during pregnancy. Physiology (Bethesda). 24: 58-71. https://dx.doi.org/10.1152\%2Fphysiol.ooo33.2008.

Palacios-Jaraquemada JM, Fiorillo A, Hamer J, Martínez M, Bruno C (2020). Placenta accreta spectrum: a hysterectomy can be prevented in almost $80 \%$ of cases using a resectivereconstructive technique. $\mathrm{J}$ Matern Fetal Neonatal Med. 1-8. https://doi.org/10.1080/14767058.2020.1716715.

Robinson BK, Grobman WA (2010). Effectiveness of timing strategies for delivery of individuals with placenta previa and accreta. Obstetr Gynecol. 116(4):835-42. https://doi.org/10.1097/aog.obo13e3181f3588d.

Sivasankar C (2012). Perioperative management of undiagnosed placenta percreta: case report and management strategies. Int J Womens Health. 4: 451-4. https://doi.org/10.2147/ijwh.s35104.

Tantbirojn P, Crum CP, Parast MM (2008). Pathophysiology of placenta creta: the role of decidua and extravillous trophoblast. Placenta. 29(7):639-45. 
Yuliantara et al./ Massive Adherent Placenta, Placenta Percreta

https://doi.org/10.1016/j.placenta.20 08.04.008.

Volochovič J, Ramašauskaitè D, Šimkevičiūtè $R$ (2016). Antenatal diagnostic aspects of placenta percreta and its influence on the perinatal outcome: a clinical case and literature review. Acta Med Litu. 23(4): 219-226.
https://dx.doi.org/10.6001\%2Factam edica.v23i4.3423.

Warshak CR, Ramos GA, Eskander R (2010). Effect of predelivery diagnosis in 99 consecutive cases of placenta accreta. Obstet Gynecol. 115(1):659.https://doi.org/10.1097/aog.obo13e 3181c4f12a. 